\title{
Premissas para a elaboração de frameworks orientados ao processo de design sob uma perspectiva sistêmica
}

\author{
Premises for the elaboration of frameworks oriented to the design process from a \\ systemic perspective
}

Maurício Elias Dick, Berenice Santos Gonçalves

processo de design, perspectiva sistêmica, frameworks, premissas

Enquanto representações visuais de sistemas e objetos de design da informação, frameworks trazem informações que apoiam a tomada de decisão, auxiliando na sustentação e no direcionamento dos projetos de forma sistêmica. Frente ao exposto, este estudo teve como objetivo propor premissas para guiar a elaboração de frameworks orientados ao processo de design sob uma perspectiva sistêmica. Tal proposição tem como base o conceito de framework e a síntese de uma revisão bibliográfica acerca das características do pensamento sistêmico, das referências teóricas sobre sistemas e dos conceitos que permitem compreender as representações sistêmicas. Em especial, destacam-se os conceitos de níveis de abstração, diagrama, grafos e regiões, pois estes colaboram diretamente para uma representação visual mais eficaz de frameworks. No total, foram formuladas nove premissas, divididas em três categorias - elementares, sistêmicas e representacionais -, que se referem ao propósito do instrumento, aos seus requisitos sistêmicos e à sua forma de organização e representação.

design process, systemic perspective, frameworks, premises

As visual representations of systems and information design objects, frameworks bring information that support decision making, assist and direct projects in a systemic way. Given that, this study proposed premises to guide the elaboration of frameworks oriented to the design process from a systemic perspective. This proposition is based on the concept of framework and on a synthesis of a bibliographic review about the characteristics of systemic thinking, theoretical references about systems and concepts that allow the understanding of systemic representations. In particular, the concepts of levels of abstraction, diagram, graphs and regions stand out, as they directly collaborate for a more effective graphic design of frameworks. In total, nine premises were formulated, divided into three categories elementary, systemic and representational -, which refer to the purpose of the instrument, its systemic requirements and its form of organization and representation.

\section{Introdução}

O cenário contemporâneo se caracteriza pelo uso de ferramentas tecnológicas em uma diversidade de atividades cotidianas. Tal confluência tecnológica modifica e faz evoluir a forma como o homem se comunica, registra informação e conhecimento e compartilha experiências (Cordon-García \& Fernández, 2015).

Anais do $10^{\circ} \mathrm{CIDI}$ e $10^{\circ} \mathrm{CONGIC}$

Kelli C.A.S. Smythe, Rafael de Castro Andrade (orgs.)

Sociedade Brasileira de Design da Informação - SBDI

Curitiba | Brasil | 2021
Proceedings of the $10^{\text {th }} \mathrm{CIDI}$ and $10^{\text {th }}$ CONGIC

Kelli C.A.S. Smythe, Rafael de Castro Andrade (orgs.)

Sociedade Brasileira de Design da Informação - SBDI Curitiba | Brazil | 2021 
Em um estudo a respeito das mudanças trazidas pela digitalização para os diferentes ramos do setor cultural e criativo, De Voldere et al. (2017) afirmam que o impacto deste fenômeno pode ser observado em diferentes níveis. Segundo os autores (De Voldere et al., 2017), de maneira geral, as novas tecnologias facilitam a criação, frequentemente reduzem os custos de produção, permitem novas formas de distribuição (como soluções em streaming), possibilitam uma promoção mais assertiva - por meio de dados mais precisos dos usuários - e modificam as formas de consumo, nas quais o indivíduo final se torna um ator ativo e não mais um consumidor passivo.

Inserido nesse contexto dinâmico, o Design se mostra como um possível agente na correta decodificação da complexidade contemporânea (Moraes, 2010), uma vez que considera os problemas de modo integrado (Cardoso, 2012). Para Cardoso (2012), umas das principais contribuições da disciplina para o equacionamento dos desafios da atualidade é a adoção do pensamento sistêmico. Há mais de duas décadas, Portas (1993) deixa explícito que um produto é apenas um componente dentro de um sistema de sistemas. Bistagnino (2009) explica que perceber o mundo de forma sistêmica implica em alargar as referências e o escopo do projeto. Com diferentes denominações, tais como "pensamento sistêmico", "visão sistêmica" e "abordagem sistêmica", este modus operandi se ocupa do contexto e das relações em um sistema, considerando os elementos e o todo (Bistagnino, 2009).

Para responder a essa demanda, porém, é necessário que se faça uso de novas abordagens projetuais, novos modelos que sustentem e direcionem o projeto (Moraes, 2010). $\mathrm{Na}$ circunstância do pensamento sistêmico, os modelos - resultados das representações de sistemas - permitem a ampliação dos processos do pensamento humano (Churchman, 2015), a melhoria no entendimento sobre determinados problemas e situações (Kasper, 2006), bem como a realização de deduções a partir de premissas, explicações e previsões (Bertalanffy, 2015). Segundo Shehabuddeen et al. (1999), modelos e frameworks compartilham de características em comum, tanto que, como explica Dix (2007), os frameworks são frequentemente referidos como modelos.

Mais especificamente, frameworks são conceituados como representações visuais de sistemas que apresentam estrutura (partes) e dinâmica (inter-relações entre as mesmas), e sua aplicação no contexto de projeto tem o intuito de aperfeiçoar o processo de design através da melhoria na qualidade da discussão entre designers, pesquisadores e outras partes interessadas, bem como auxiliar no desenvolvimento de métodos e ferramentas de implementação ${ }^{1}$ (Dick \& Gonçalves, 2019b; Ideo, 2015; Rogers \& Muller, 2006). Na forma de diagramas, trazem informações visualmente ordenadas que podem orientar a tomada de decisão de modo eficaz e eficiente (Dick et al., 2017). Por serem intencionalmente criados para

\footnotetext{
${ }^{1}$ Para Rogers et al. (2013), um framework oferece conselhos - como, por exemplo, o que projetar ou procurar - e auxilia no planejamento e na lembrança das questões pertinentes a um projeto, podendo se configurar em uma diversidade de formas, como etapas, perguntas, conceitos, desafios, princípios, táticas ou dimensões. Rogers e Muller (2006) explicam que quanto mais prescritivo for o framework, maiores as chances de consistir em uma série de etapas ou princípios a serem seguidos. Em contrapartida, quanto mais explicativo, mais provável que consista em um conjunto de conceitos ou dimensões a serem considerados.
} 
esse fim informacional, frameworks podem ser considerados representações gráficas - tal como o conceito trazido Engelhardt (2002) - e se inserem no campo do design da informação.

Frente ao exposto, este estudo buscou contribuir para a construção de instrumentos que permitam a visualização da complexidade design de artefatos diversos e teve como objetivo propor premissas para guiar a elaboração de frameworks orientados ao processo de design sob uma perspectiva sistêmica. Tal proposição tem como base o conceito de framework e a síntese de uma revisão bibliográfica acerca das características do pensamento sistêmico, das referências teóricas sobre sistemas e dos conceitos que permitem compreender as representações sistêmicas.

\section{Epistemologia, teoria e prática sistêmica}

O pensamento sistêmico se baseia "nas ideias sistêmicas de primazia dos relacionamentos, da circularidade, da rede, dos processos dinâmicos e do todo" (Andrade, 2014, p. 8). Essa maneira de pensar é conhecida como "pensamento por meio de sistemas" e envolve um pensamento que se processa mediante relações, padrões e contextos (Capra \& Luisi, 2014). Capra e Luisi (2014) explicitam que as diferentes características do pensamento sistêmico implicam, em essência, em uma troca de perspectiva. Uma mudança de percepção de objetos e estruturas materiais para processos e padrões de organização não materiais. No entanto, cabe reforçar que essa ênfase nas relações, nas qualidades e nos processos não acarreta a eliminação da importância de objetos, quantidades e estruturas. O pensamento sistêmico não exclui o ponto de vista contrário, mas sugere uma interação complementar entre ambos.

\section{Conceitos advindos das teorias sistêmicas}

Diferentes teorias desenvolvidas ao longo dos últimos 100 anos permitiram caracterizar a forma de pensar sistêmica. Conforme Kasper (2006), o movimento sistêmico não se consolidou sob um quadro teórico único, sendo composto por um leque amplo de concepções sistêmicas (conceitos, noções e princípios gerais), modelos teóricos focalizados em conteúdos disciplinares, além de métodos e ferramentas para a solução de problemas específicos. Entretanto, não são as teorias especificamente que interessam a este estudo, mas os conceitos que estas trouxeram e que contribuem para a compreensão do pensamento sistêmico.

A primeira concepção que orienta o pensamento sistêmico é a própria definição de sistema. Diversos autores conceituam o termo e acabam convergindo em alguns aspectos. Segundo Churchman (2015, p. 27), os sistemas "são constituídos de conjuntos de componentes que atuam juntos na execução do objetivo global do todo". Nessa direção, todo sistema tem ao menos um propósito ou objetivo, que define o arranjo de seus elementos e seus relacionamentos (Chiavenato, 2011).

Similarmente, Alves (2012) explica que um sistema é uma construção mental que contém uma coleção de elementos inter-relacionados, constituindo um todo (uma unidade) com alguma funcionalidade específica. Conforme Andrade (2014, p. 6), um sistema é "um conjunto de 
elementos, concretos ou abstratos, intelectualmente organizado e orientado para um fim". Com o mesmo enfoque, Chiavenato (2011, p. 390) complementa que "os elementos, as relações entre eles e os objetivos (ou propósitos) constituem os aspectos fundamentais da definição de um sistema". Para Bertalanffy (2015), um sistema é um conjunto de elementos que se relacionam entre si e com o ambiente no qual o sistema está inserido.

É importante perceber que as partes de um sistema também podem ser consideradas sistemas, chamados de subsistemas, que, por sua vez, são formados pela reunião de novos subsistemas, mais detalhados, dependendo do nível de complexidade do conjunto apreciado (Chiavenato, 2011). No movimento contrário, tem-se um agregado de sistemas, o suprasistema ou supersistema (Alves, 2012; Chiavenato, 2011). Em suma, tudo é um sistema ou uma parte de um sistema, podendo este conceito ser aplicado a diferentes níveis de abordagem (Bunge, 2014; Chiavenato, 2011).

Sendo parte de um contexto, todo sistema está inserido em um ambiente, tendo seus limites definidos pela sua fronteira (Figura 1). Quem faz a delimitação dessa fronteira, concebendo o que faz parte do sistema o que está no ambiente é o observador. É este quem divide um espaço - seja físico ou virtual - em sistema e ambiente, definindo a fronteira entre os dois (Alves, 2012).

Figura 1: Ambiente, fronteira e sistema. Fonte: dos autores a partir de Alves (2012).

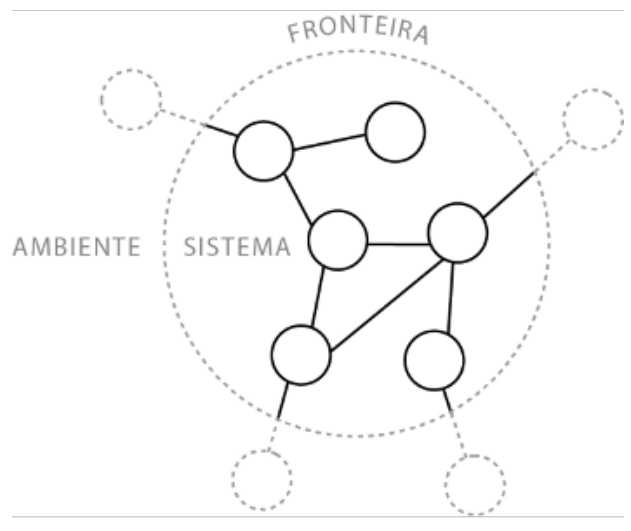

Assim, a reflexão sobre dados aspectos observados da realidade pode levar o observador, por via da abstração, a isolar alguns que lhe pareçam relevantes. Se estes aspectos possuírem relações capazes de formar uma unidade funcional, tem-se a concepção de um sistema (Alves, 2012). Na avaliação destas relações, Bunge (2014) faz uma ressalva: nem tudo está ligado a tudo e nem todas as ligações são igualmente fortes. Isso torna o isolamento parcial possível e permite o estudo de determinados elementos sem considerar outros.

Bunge (2014) explica que a noção de sistema como um conjunto de ligações só permite reconhecê-lo a partir do momento que se revela sua estrutura. Como afirma Capra (2006), as propriedades sistêmicas são propriedades que surgem da configuração de relações característica de um sistema particular, seu padrão de organização. "O padrão de organização de qualquer sistema, vivo ou não vivo, é a configuração de relações entre os componentes do 
sistema", que determina suas características essenciais (Capra \& Luisi, 2014, p. 373; Maturana \& Varela, 2011). Isto é, determinadas relações devem estar presentes para que algo seja distinguido como tal.

A estrutura de um sistema, por seu turno, é a incorporação física do seu padrão de organização, envolvendo a descrição dos componentes do sistema, podendo ser fixa ou variável (Alves, 2012). Finalmente, a perspectiva do processo é a ligação entre organização e estrutura (Capra \& Luisi, 2014). Dessa forma, organização, estrutura e processo são perspectivas interdependentes, diferentes, mas inseparáveis (Capra \& Luisi, 2014), havendo sempre uma relação entre eles. Um sistema opera de determinada forma em razão das relações entre os seus componentes (Alves, 2012). São os processos que estabelecem padrões de organização e seu reconhecimento traz a consciência da estrutura (Andrade et al., 2006; Andrade, 2014).

No entanto, na prática Bunge (2014) deixa claro que essas noções sistêmicas são utilizadas em um dado nível, pois não é possível conhecer todas as partes e todas suas interações, nem todas as ligações com o ambiente em todos os níveis do sistema.

\section{Representação sistêmica}

Sabe-se que um sistema é uma construção mental realizada pelo observador em um determinado contexto, sendo uma representação da realidade (Alves, 2012; Vassão, 2010). Essa representação envolve a descrição da realidade, ou parte dela, o que implica, segundo Vassão (2010), em uma redução da mesma.

Isto se dá, pois é praticamente impossível lidar com a realidade sem que se faça o uso de representações (Vassão, 2010), dadas as limitações da cognição humana e a complexidade do mundo real. Com isso, este movimento resulta em uma simplificação, um ato criativo e subjetivo. É essencial ter consciência que este ato não permite um conhecimento completo e definitivo sobre o mundo, mas sim temporário, circunstancial e incompleto, que pode ser aplicado em diversos contextos, mas não em todos (Vassão, 2010).

Para Alves (2012), a construção mental de um sistema também envolve abstração. O autor (Alves, 2012) explica que a abstração permite que se separe alguns elementos de uma complexa totalidade, reservando partes relevantes baseadas no julgamento individual e na visão panorâmica do todo. Vassão (2010) lembra que a abstração ocorre em diferentes níveis, indicando variados graus de complexidade dependendo das entidades consideradas. Cada patamar de "encapsulação" indica um nível de abstração.

Organizar representações, mediante abstração e simplificação, resulta em modelos. Estes são entidades que explicam o funcionamento de uma determinada realidade ou parte dela, servindo como referência para a construção, avaliação e controle de algo (Vassão, 2010). Eles procuram representar certos aspectos - de forma simplificada e por isso compreensível - e são a base de qualquer tentativa teórica (Bertalanffy, 2015). Tal como explica Vassão (2010) ao justificar o uso de representações, Bertalanffy (2015) afirma que é necessário reduzir a realidade a um esqueleto conceitual para tornar o modelo conceitualmente utilizável. 
Ao modelar um sistema, como não é possível descrevê-lo de forma exata e explícita, buscam-se seus aspectos mais significativos, o que acaba por reduzir sua complexidade (Alves, 2012). Desse modo, é importante descrever sua funcionalidade, seus componentes (ou os mais relevantes) e averiguar as relações entre eles. Além disso, descreve-se o ambiente no qual o sistema está inserido, destacando diferenças para evidenciar o que pertence ao sistema e o que faz parte do meio. Deve-se repetir este movimento até que se consiga a melhor síntese do sistema em estudo (Alves, 2012).

Para Vassão (2014), os sistemas são mais facilmente percebidos, organizados e operacionalizados se visualizados como diagramas. Aplicados juntos dos princípios da topologia (um campo de estudo da matemática), eles permitem "localizar" o sistema: compreendê-lo por meio de configurações que demonstrem o arranjo de suas conexões, forças e fluxos.

Nessa direção, o autor (Vassão, 2010) aponta que dois conceitos são suficientes para compreender a aplicação da topologia na criação de diagramas. O primeiro deles é o conceito de grafos. Os grafos são figuras compostas por entidades conectadas por relações. Estas entidades podem ser representadas por formas geométricas ou qualquer outra imagem, enquanto as relações podem ser linhas retas, curvas, caminhos etc. Juntos, as entidades e suas relações formam nós em uma rede e suas conexões.

A segunda concepção que Vassão (2010) destaca diz respeito ao conceito de regiões. Estas são áreas, volumes ou massas que delimitam algum campo ou espaço. As regiões são definidas por uma fronteira, que separa o espaço dentro e fora da região, indicando os limites de um conjunto ou grupo de entidades. Assim, grafos podem estar organizados em regiões e, de forma conjunta, ambos os conceitos permitem compreender o modo como algo está configurado, isto é, sua conformação topológica (Vassão, 2010). A Figura 2 mostra exemplos destas conformações.

Figura 2: Arranjos de grafos, suas relações e regiões em diferentes conformações. Fonte: adaptado de Vassão (2010).
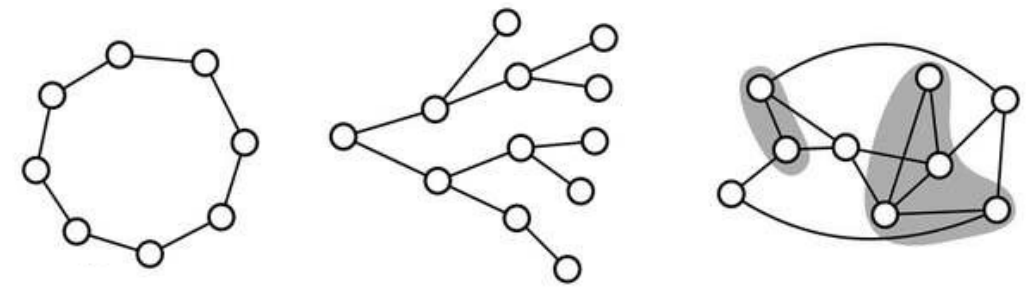

O diagrama de um modelo tende a ser uma rede, composto por componentes organizados, e explicita tanto representação quanto funcionamento, evidenciando a operação e a conexão das entidades. Ainda, os diagramas permitem "a identificação de processos recorrentes, tipologias e aglutinações - envolvendo elementos tecnológicos, ambientais e sociais" (Vassão, 2010, p. 59). Cabe mencionar que existem diversas linguagens que modelam a dinâmica de 
um sistema e que também permitem a representação da rede de inter-relacionamentos. $A$ Figura 3 apresenta um exemplo.

Figura 3: Exemplo de diagrama. Fonte: Borgmeyer (2017).

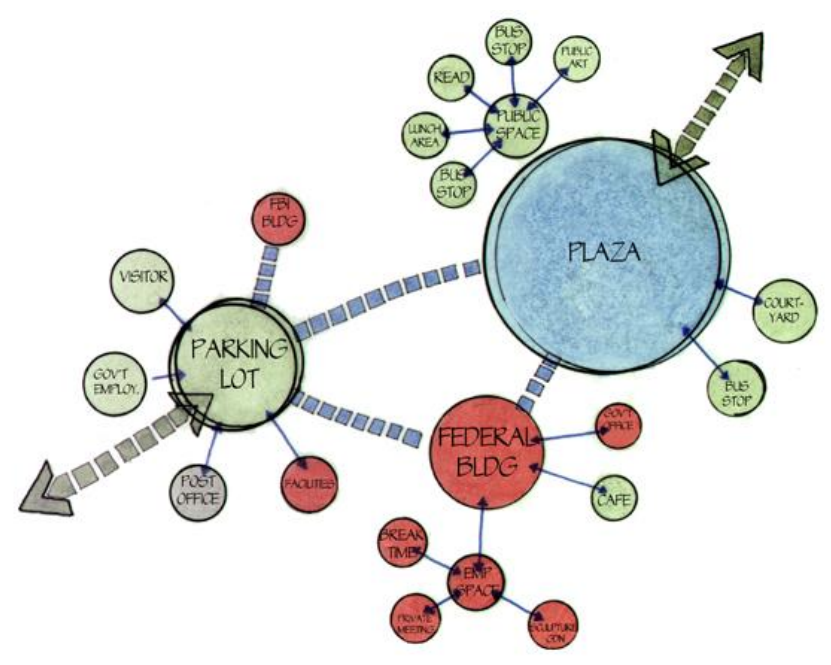

De toda forma, interessa ao escopo desta pesquisa a forma de representar sistemas de modo genérico e não na especificidade dos diferentes tipos de diagramas. Como afirma Andrade (2014), a linguagem visual, provida por técnicas de expressão visual, ajuda a perceber nos sistemas os relacionamentos, as circularidades, as redes e os processos de um ponto de vista dinâmico e geral. Por consequência, há várias maneiras de representar um sistema e sua escolha recai no uso que será feito da representação (Alves, 2012).

\section{Procedimentos para a formulação das premissas}

A formulação das premissas teve como base a definição de framework e a síntese dos dados e conhecimentos levantados na revisão de literatura a respeito do pensamento sistêmico. Já, o tratamento dos dados coletados se deu de forma qualitativa, a partir da interpretação dos pesquisadores.

Para tal, fez-se uso o método de análise de conteúdo proposto por Bardin (2016), organizado em três momentos: (i) pré-análise, correspondendo à fase de organização da análise; (ii) exploração do material, a qual se refere à fase de análise propriamente dita; e (iii) tratamento dos resultados obtidos e interpretação, momento no qual os resultados brutos são tratados de maneira a serem significativos e válidos para propor inferências e adiantar interpretações a propósito do objetivo previsto.

Dessa forma, os procedimentos se organizaram nas seguintes etapas: (1) revisão de literatura, (2) síntese dos achados teóricos (pré-análise), (3) categorização dos conhecimentos (exploração do material) e (4) redação das premissas (tratamento dos 
resultados obtidos e interpretação). Convém destacar que as etapas 3 e 4 ocorreram de forma cíclica até se efetivarem a categorização e a redação das premissas finais.

Assim, a primeira categoria proposta se refere às premissas elementares. Este conjunto diz respeito à definição da natureza, do propósito e da configuração formal do framework, contemplando suas características básicas. Para sua formulação, foram utilizados os conhecimentos sintetizados no Quadro 1.

Quadro 1: Autores e conhecimentos que moldaram as premissas elementares. Fonte: dos autores.

\begin{tabular}{ll}
\hline Autores & Conhecimentos que moldaram as premissas elementares \\
\hline $\begin{array}{l}\text { (Dick \& Gonçalves, } \\
\text { 2019b; Ideo, 2015) }\end{array}$ & $\begin{array}{l}\text { Um framework pode ser conceituado como a representação visual de um } \\
\text { sistema que mostra seus diferentes elementos e agentes (estrutura), } \\
\text { evidenciando as relações ali presentes (dinâmica). }\end{array}$ \\
(Rogers et al., 2013) & $\begin{array}{l}\text { Um framework pode oferecer conselhos - como, por exemplo, o que projetar } \\
\text { ou procurar - e pode auxiliar no planejamento e na lembrança das questões }\end{array}$ \\
& pertinentes a um projeto. \\
(Rogers et al., 2013; & $\begin{array}{l}\text { Um framework pode se configurar em uma diversidade de formas, como } \\
\text { etapas, perguntas, conceitos, desafios, princípios, táticas ou dimensões. } \\
\text { Quanto mais prescritivo for o framework, maiores as chances de consistir em }\end{array}$ \\
& $\begin{array}{l}\text { uma série de etapas ou princípios a serem seguidos. Em contrapartida, } \\
\text { quanto mais explicativo, mais provável que consista em um conjunto de } \\
\text { conceitos ou dimensões a serem considerados. }\end{array}$ \\
\hline
\end{tabular}

A segunda categoria, das premissas sistêmicas, especifica os requisitos para que 0 framework contemple uma visão sistêmica do processo de design. O Quadro 2 apresenta os conhecimentos que moldaram este grupo.

Quadro 2: Autores e conhecimentos que moldaram as premissas sistêmicas. Fonte: dos autores.

\begin{tabular}{ll}
\hline Autores & Conhecimentos que moldaram as premissas sistêmicas \\
\hline (Alves, 2012) & $\begin{array}{l}\text { Como parte de um contexto, todo sistema sempre está inserido em um } \\
\text { ambiente, tendo seus limites definidos pela sua fronteira, delimitada pelo } \\
\text { observador. }\end{array}$ \\
$\begin{array}{l}\text { (Chiavenato, 2011; } \\
\text { Andrade, 2014; Andrade }\end{array}$ & $\begin{array}{l}\text { Todo sistema tem ao menos um propósito ou objetivo, que define o arranjo } \\
\text { de seus elementos e seus relacionamentos. São os processos que } \\
\text { estabelecem padrões de organização e seu reconhecimento traz a } \\
\text { consciência da estrutura. }\end{array}$ \\
\hline
\end{tabular}

Por fim, a terceira categoria - das premissas representacionais - define as características da representação visual framework. Sua elaboração se pautou nos conhecimentos resumidos no Quadro 3. 
Quadro 3: Autores e conhecimentos que moldaram as premissas representacionais. Fonte: dos autores.

\begin{tabular}{ll}
\hline Autores & Conhecimentos que moldaram as premissas representacionais \\
\hline (Alves, 2012; Vassão, & Um sistema é uma representação reduzida da realidade. \\
2010; Bertalanffy, 2015) & $\begin{array}{l}\text { Tal redução é necessária para torná-la um esqueleto conceitual } \\
\text { conceitualmente utilizável. Já a abstração permite que se separe alguns } \\
\text { elementos de uma complexa totalidade. Ela ocorre em diferentes níveis, } \\
\text { indicando variados graus de complexidade dependendo das entidades } \\
\text { consideradas. Cada patamar de "encapsulação" indica um nível de } \\
\text { abstração. } \\
\text { Há várias maneiras de representar um sistema e sua escolha recai no uso } \\
\text { que será feito da representação. Os sistemas, por sua vez, são mais } \\
\text { facilmente percebidos, organizados e operacionalizados se visualizados } \\
\text { como diagramas } \\
\text { Grafos são entidades conectadas por relações e regiões são áreas, volumes } \\
\text { ou massas que delimitam algum campo ou espaço. De forma conjunta, } \\
\text { ambos permitem compreender o modo como algo está configurado e são } \\
\text { (Vassão, 2010; Capra \& 2014) }\end{array} \quad \begin{array}{l}\text { essenciais na criação de diagramas. O diagrama de um modelo (logo, um } \\
\text { sistema) tende a ser uma rede, pois o modo de pensar sistêmico é em redes } \\
\text { e não linear. } \\
\text { Ao modelar um sistema, como não é possível descrevê-lo de forma exata e } \\
\text { explícita, buscam-se seus aspectos mais significativos, o que acaba por } \\
\text { reduzir sua complexidade. }\end{array}$ \\
\hline
\end{tabular}

\section{Resultados e discussões}

Como resultado, tem-se o Quadro 4 que apresenta nove premissas propostas para a elaboração de frameworks orientados ao processo de design sob uma perspectiva sistêmica. Junto destas, foram trazidas observações complementares, organizadas a partir dos conhecimentos apresentados anteriormente.

É relevante compreender que o conjunto está relacionado aos conceitos geradores do todo, tendo caráter amplo, podendo ser aplicável ao desenvolvimento de qualquer framework que tenha o intuito de contemplar uma representação sistêmica relacionada a um processo de design. As premissas se referem ao propósito do instrumento, aos seus requisitos sistêmicos e à sua forma de organização e representação. Assim, se dividem em elementares, sistêmicas e representacionais.

Quadro 4: Premissas propostas neste estudo. Fonte: dos autores.

\begin{tabular}{llll}
\hline Categoria & Número & Premissa & Observações \\
\hline Elementar & 1 & $\begin{array}{l}\text { O framework orientado ao processo } \\
\text { de design é uma representação } \\
\text { visual de um sistema. }\end{array}$ & $\begin{array}{l}\text { Um framework mostra os } \\
\text { diferentes elementos e agentes } \\
\text { (estrutura) do sistema, }\end{array}$ \\
& & $\begin{array}{l}\text { evidenciando as relações } \\
\text { (dinâmica) entre eles. }\end{array}$
\end{tabular}




\begin{tabular}{|c|c|c|c|}
\hline Categoria & Número & Premissa & Observações \\
\hline Elementar & 2 & $\begin{array}{l}\text { Tal framework auxilia na } \\
\text { demarcação e planejamento de } \\
\text { questões pertinentes ao processo de } \\
\text { design. }\end{array}$ & $\begin{array}{l}\text { Um framework pode oferecer } \\
\text { conselhos, por exemplo, o que } \\
\text { projetar, fazer, procurar ou } \\
\text { considerar. }\end{array}$ \\
\hline Elementar & 3 & $\begin{array}{l}\text { Quando de caráter explicativo, o } \\
\text { framework pode ser configurado } \\
\text { como um conjunto de conceitos, } \\
\text { perguntas, dimensões ou fatores a } \\
\text { serem considerados no processo de } \\
\text { design. Quando de caráter } \\
\text { prescritivo, o framework pode } \\
\text { consistir em uma série de etapas ou } \\
\text { princípios a serem seguidos no } \\
\text { referido processo. }\end{array}$ & $\begin{array}{l}\text { Um framework pode se } \\
\text { configurar em uma diversidade } \\
\text { de formas, de acordo com o seu } \\
\text { caráter (explicativo ou } \\
\text { prescritivo), determinado em } \\
\text { razão do seu propósito. }\end{array}$ \\
\hline Sistêmica & 4 & $\begin{array}{l}\text { O framework orientado ao processo } \\
\text { de design delimita sistema e } \\
\text { ambiente, evidenciando a fronteira } \\
\text { entre ambos. }\end{array}$ & $\begin{array}{l}\text { Como parte de um contexto, } \\
\text { todo sistema sempre está } \\
\text { inserido em um ambiente, tendo } \\
\text { seus limites definidos pela sua } \\
\text { fronteira. }\end{array}$ \\
\hline Sistêmica & 5 & $\begin{array}{l}\text { O sistema delimitado no framework } \\
\text { é definido pelo processo de design } \\
\text { do artefato em questão, o qual } \\
\text { determina seus componentes, o } \\
\text { arranjo dos mesmos e seus } \\
\text { relacionamentos. }\end{array}$ & $\begin{array}{l}\text { Todo sistema tem um propósito } \\
\text { ou objetivo, cujo processo } \\
\text { estabelece o padrão de } \\
\text { organização dos seus } \\
\text { elementos. }\end{array}$ \\
\hline Representacional & 6 & $\begin{array}{l}\text { O framework orientado ao processo } \\
\text { de design é uma representação } \\
\text { visual simplificada, que possui um } \\
\text { número limitado de níveis de } \\
\text { abstração. }\end{array}$ & $\begin{array}{l}\text { Tal simplificação é necessária } \\
\text { para tornar a representação } \\
\text { utilizável. A abstração ocorre } \\
\text { em diferentes níveis, indicando } \\
\text { variados graus de complexidade } \\
\text { dependendo das entidades } \\
\text { consideradas. }\end{array}$ \\
\hline Representacional & 7 & $\begin{array}{l}\text { O framework orientado ao processo } \\
\text { de design pode ser representado de } \\
\text { diferentes maneiras. Sobretudo, a } \\
\text { forma de diagrama permite que o } \\
\text { instrumento seja mais facilmente } \\
\text { percebido, organizado e } \\
\text { operacionalizado. }\end{array}$ & $\begin{array}{l}\text { A escolha pela forma de } \\
\text { representação do framework } \\
\text { recai no uso que será feito do } \\
\text { mesmo. }\end{array}$ \\
\hline Representacional & 8 & $\begin{array}{l}\text { Quando na forma de diagrama, o } \\
\text { framework orientado ao processo de } \\
\text { design é composto por grafos e } \\
\text { regiões em um arranjo em rede, } \\
\text { não-linear. }\end{array}$ & $\begin{array}{l}\text { Os grafos são entidades } \\
\text { conectadas por relações. Já as } \\
\text { regiões são áreas, volumes ou } \\
\text { massas que delimitam um } \\
\text { campo ou espaço. }\end{array}$ \\
\hline
\end{tabular}




\begin{tabular}{llll}
\hline Categoria & Número & Premissa & Observações \\
\hline Representacional & 9 & O framework orientado ao processo & Ao modelar um sistema, é \\
& & de design contempla os aspectos & preciso reduzir sua \\
& mais significativos do sistema, & complexidade, pois é inviável \\
& determinados por premissas & descrevê-lo de forma completa. \\
& específicas dirigidas ao contexto do & \\
& artefato em questão. & \\
\end{tabular}

É importante destacar que a definição do caráter e do conteúdo do framework a ser elaborado a partir das premissas aqui apresentadas depende do objeto de design cuja proposta está direcionada, tal como evidenciam as premissas 3 e 5 . Assim, para cada framework a ser construído, cabe a definição de premissas específicas que dão conta das particularidades relacionadas ao objeto de estudo e ao sistema que influencia o seu processo de design.

Nessa direção, a compreensão do conceito de sistema enquanto um conjunto de partes inter-relacionadas, organizadas e direcionadas para um fim, bem como a noção dos variados níveis sistêmicos auxiliam na caracterização do processo de design como um sistema e na compreensão de que seus componentes igualmente podem ser visualizados como sistemas passíveis de modelagens próprias, a depender do enfoque dado pelo observador. A título de exemplo, a Figura 4 apresenta um framework orientado ao processo de design de livros digitais, cujo detalhamento de construção e propósito se encontra disponível em Dick \& Gonçalves (2019a). 
Figura 4: Exemplo de framework orientado ao processo de design sob uma perspectiva sistêmica. Fonte: Dick \& Gonçalves (2019a).

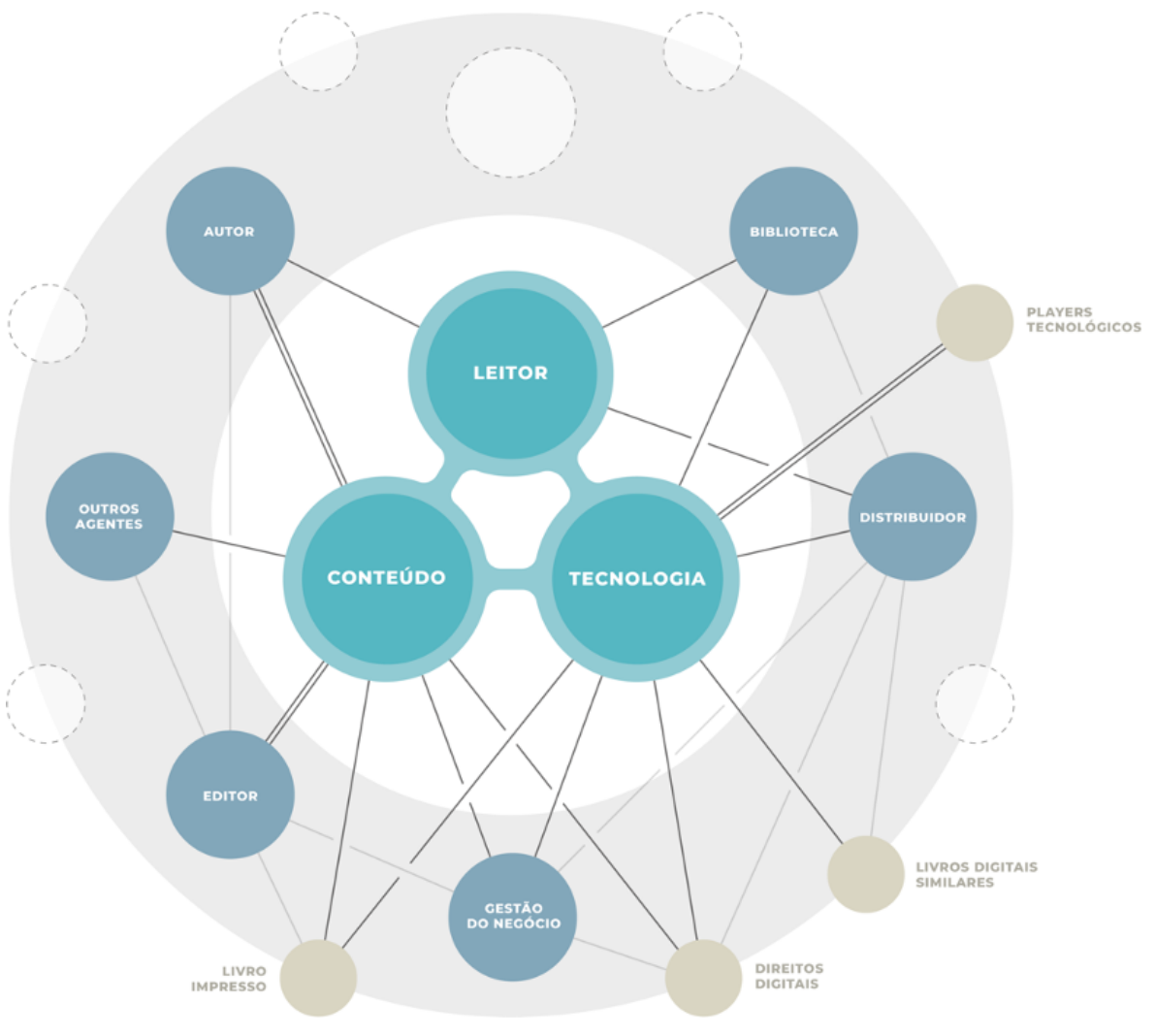

\section{Considerações finais}

A complexidade dos problemas de design aumenta à medida que o cenário contemporâneo se apresenta cada vez mais dinâmico e inter-relacionado. Nesse contexto, o ato de projetar deve levar em consideração variadas dimensões interconectadas, que vão além do design do artefato em si. Isto é, projetar envolve a compreender um sistema. Diante disso, entende-se que é preciso adotar uma perspectiva sistêmica para alargar a visão do escopo dos projetos e responder de forma mais adequada às demandas da realidade atual. Enquanto representações visuais de sistemas e objetos de design da informação, frameworks vão ao encontro dessa necessidade, pois trazem informações que orientam a tomada de decisão, auxiliando na sustentação e no direcionamento dos projetos de forma sistêmica.

Isto posto, esta pesquisa teve como objetivo propor premissas para guiar a elaboração de frameworks orientados ao processo de design sob uma perspectiva sistêmica. A revisão teórica permitiu entender diferentes conceitos substanciais relacionados ao pensamento sistêmico como sistema, ambiente, estrutura, organização e processo -, além das características deste modo de pensar e das representações sistêmicas. Tal arcabouço teórico foi essencial para a formulação das premissas elementares, sistêmicas e representacionais, visando a elaboração de frameworks que possibilitem uma visão sistêmica da complexidade do processo de design de diferentes artefatos. Destacam-se em especial os conceitos relacionados à representação 
sistêmica, tais como níveis de abstração, diagrama, grafos e regiões, pois estes colaboram diretamente para uma representação visual mais eficaz de frameworks.

Finalmente, reconhece-se que alguns dos autores pesquisados são proponentes de teorias e outros são comentadores ou intérpretes das mesmas, os quais auxiliam a entendê-las de maneira aplicada. Apesar de um certo ecletismo nas fontes adotadas, julgou-se que eventuais diferenças conceituais não prejudicaram a pesquisa, porque neste estudo se fez necessária a compreensão dos conceitos sistêmicos apenas em um nível suficiente para que fosse possível sua transposição para o universo do processo de design. Nesse sentido, considerou-se que os autores trazidos foram aqueles que trouxeram melhores insights e permitiram transferir com mais facilidade os conceitos para o contexto da pesquisa.

\section{Referências}

Alves, J. B. M. (2012). Teoria geral de sistemas: em busca da interdisciplinaridade. Florianópolis: Instituto Stela.

Andrade, A. L. et al. (2006). Pensamento sistêmico: caderno de campo. Porto Alegre: Bookman.

Andrade, A. L. (2014). O Curso do Pensamento Sistêmico. São Paulo: Digital Publish \& Print. Bardin, L. (2016). Análise de conteúdo. São Paulo: Edições 70.

Bertalanffy, L. (2015) Teoria geral dos sistemas: fundamentos, desenvolvimento e aplicações. 8. ed. Petrópolis, RJ: Vozes.

Bistagnino, L. (2009). Design sistêmico: uma abordagem interdisciplinar para a inovação. In: Moraes, D., \& Krucken, L. (2009). Design e sustentabilidade. Cadernos de estudos avançados em Design. Barbacena, MG: EdUEMG. p. 13-29.

Bunge, M. (2014). Emergencia y Convergencia: Novedad Cualitativa y Unidad del Conocimiento. Barcelona: Editorial Gedisa.

Capra, F. (2006). A teia da vida: uma nova compreensão científica dos sistemas vivos. São Paulo: Cultrix.

Capra, F., \& Luisi, P. L. (2014). A visão sistêmica da vida: uma concepção unificada e suas implicações filosóficas, políticas, sociais e econômicos. São Paulo: Cultrix.

Cardoso, R. (2012). Design para um mundo complexo. São Paulo: Cosac Naify.

Chiavenato, I. (2011). Introdução à Teoria Geral da Administração. 8. ed. Rio de Janeiro: Elsevier.

Churchman, C. W. (2015). Introdução à Teoria dos Sistemas. 2. ed. Petrópolis, RJ: Vozes.

Cordon-García, J. A., \& Fernández, A. O. J. (2015). Is Reading and Writing Being Transformed in this Digital Age?. Rev. Interam. Bibliot. Medellín (Colombia), v. 38, n. 2, p. 137-145.

De Voldere, I. et al. (2017). Mapping the Creative Value Chains: A study on the economy of culture in the digital age. Final report. Luxembourg: Publications Office of the European Union, 2017. Disponível em: https://publications.europa.eu/s/fo2x. 
Dick, M. E., \& Gonçalves, B. S. (2019a). O pensamento sistêmico no processo de design de livros digitais: a proposta "Framebook". Estudos em Design, 27(3).

Dick, M. E., \& Gonçalves, B. S. (2019b). Representações e abordagens de apoio ao design do livro digital, p. 2640-2651. In: Anais do $13^{\circ}$ Congresso Pesquisa e Desenvolvimento em Design (2018). São Paulo: Blucher. ISSN 2318-6968, DOI 10.5151/ped2018-3.3_ACO_71.

Dick, M. E., Gonçalves, B. S., \& Vitorino, E. V. (2017). Design da informação e competência em informação: relações possíveis. INFODESIGN (SBDI. ONLINE), v. 14, p. 1-13.

Dix, K. L. (2007). DBRIEF: A research paradigm for ICT adoption. International Education Journal, v. 8, n. 2, p. 113-124.

Engelhardt, Y. (2002). The language of graphics: a framework for the analysis of syntax and meaning in maps, charts and diagrams. Amsterdam: ILLC Publications.

Ideo. (2015). Human Centered Design: kit de ferramentas. 2. ed. Disponível em: http://www.designkit.org/resources/1.

Kasper, H. (2006). Perspectivas em Pensamento Sistêmico. In: Andrade, A. L. et al. (2006). Pensamento sistêmico: caderno de campo. Porto Alegre: Bookman, 2006.

Maturana, H. R., \& Varela, F. J. (2011). A árvore do conhecimento: as bases biológicas da compreensão humana. 9. ed. São Paulo: Palas Athena.

Moraes, D. (2010). Metaprojeto: o design do design. São Paulo: Blucher.

Portas, N. (1993). In: Calçada, A., Mendes, F., \& Barata, M. (1993). Design em aberto: uma antologia. Porto, Portugal: Centro Português de Design.

Rogers, Y., \& Muller, H. (2006). A framework for designing sensor-based interactions to promote exploration and reflection in play. International Journal of Human-Computer Studies, v. 64, n. 1, p. 1-14. Disponível em: http://doi.org/10.1016/j.ijhcs.2005.05.004.

Rogers, Y., Sharp, H., \& Preece, J. (2013). Design de Interação: além da interação homemcomputador. Porto Alegre: Bookman.

Shehabuddeen, N. et al. (1999). Representing and approaching complex management issues: part 1 - role and definition. Centre for Technology Management Working Paper Series. Cambridge, 1-20.

Vassão, C. A. (2010). Metadesign: ferramentas, estratégias e ética para a complexidade. São Paulo: Blucher.

\section{Sobre os autores}

Maurício Elias Dick, Doutor, Universidade do Estado de Santa Catarina, Brasil <mauricioedick@gmail.com>

Berenice Santos Gonçalves, Doutora, Universidade Federal de Santa Catarina, Brasil <berenice@cce.ufsc.br> 